\section{Military Occupational Status}

Racine Brown

Center of Innovation on Disability and

Rehabilitation Research, James A. Haley

Veterans' Hospital, Tampa, FL, USA

\section{Synonyms}

Air force specialty codes; Naval ratings

\section{Definition}

A military occupational specialty (MOS) is a formal designation of occupational skill rating and a job title. An MOS and accompanying description indicate broad occupational categories, specific job categories, and a specific job description. For instance, the Marine Corps has the broad category of combat arms, with the 0300 series denoting infantry personnel, 0311 rifleman, 0331 machine gunner, 0369 infantry unit leader, and 0302 infantry officer. MOS is denoted by a four-digit number in the Marine Corps and a letter-number combination in the Army. The Navy and Air Force use similar alphanumeric systems to designation specialties but refer to them by different names than MOS.

\section{See Also}

- Department of Defense

Deployment

- Military Discharge and Types

\section{References}

Military 1. (2017). MOS codes. Retrieved from https://www. military1.com/all-enlistment/318809-marine-corps-moscodes/.

United States Army. (2017). Army jobs=military occupational specialties. Retrieved from http://army.com/info/ mos/all.

Wikipedia. (2017). United States military occupation code. Retrieved from https://en.wikipedia.org/wiki/United States_military_occupation_code. 